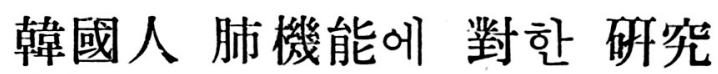

\author{
一職 業 別 檢 討--
}

\author{
吳重根・金才媛・鄭惠英
}

\author{
國立醫療院 胸廓內科
}

\section{Studies on the Lung Function of the Korean}

\author{
J.K. Oh, M.D., J.W. Kim, M.D. \& H.Y. Chung, M.D. \\ Dept. of Chest Medicine, The National Medical Center, Seoul, Korea.
}

For the purpose of evaluating the lung function of jet pilots and coal miners, we measured Vit. Cap. with a special reference which was assistance to corelation with cardiac function, a study was carried out on 271 jet pilots and 47 coal miners and the results are summarized as follows:

1. Of respiration, $17 / \mathrm{min}$ of the jet pilot and $16 / \mathrm{min}$ of the workers.

2. For vital capacity of jet pilots was about 5 Lit., 3.2 Lit in mine workers, which is uniformaly $20 \%$ higher in jet pilots and lower in mine workers than standard value.

3. Tidal volume was $500 \mathrm{ml}$ and maximal breathing capacity was 110 liters per minute for both jet pilot and workers.

4. Breath holding time was 45 second for jet pilots and 54 second for coal miners which was 10 second lower in workers than jet pilots.

\section{I. 緒 論}

우리나라게서는 其間 肺機能에 對하여 各 職業別로 䂰究가 進行되고 發表된바 있지 만 ${ }^{1,2,3,4)}$ 綜合的으로 比

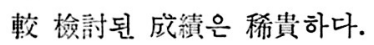

國民體力의 重要한 位置를 차지하는 肺機能에 對한 綜合的인 考察를 하여 評價함으로서 體格과의 關係 5,63

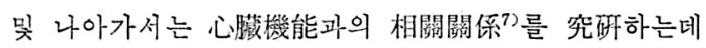
도움이 될 것이다.

著者들은 今般 特殊 分野인 空軍 操縱士 및 鍰夫(全 南和順炭鑛) 에 激하여 主로 肺活量을 測定하여 그 檢 查成績을 報告하는 同㭙에 只今까.지 報告된 成績과 比 較 檢討하였다.

\section{II. 調査對象 吕 方法}

本調查의 對象으로는 271 名의 身體缺陷이 없는 空軍
Jet機 操縦士와 鐄夫 47 名, 總 318 名 이였다.

\section{1. 年齢 吕體格}

操縱士의 年龄은 22 歲로 부터 36 歲까지이며 그 平均 年喰은 28 歲이다. 그리고 鐄夫의 年跲은 18 歲로 부터 45藏까지 이며 平均年粮은 32歲이다. 體格에 있어서는 操䅠士에 있어서 平均身長이 $168.5 \mathrm{~cm}$ 이며, 鍰夫에 있 어서 는 $160 \mathrm{~cm}$ 이다. 體重은 操緃士에 서 平均 $63.4 \mathrm{~kg}$ 이 고 鐄夫에 서 는 $59.2 \mathrm{~kg}$ 으로서 이에 體表面積을 보면 各 各 $1,725 / \mathrm{m}^{2}( \pm 0.096)$ 와 $1,690 / \mathrm{m}^{2}( \pm 0.680)$ 이었다(第 1表).

\section{2. 檢查方法}

\section{1) 體表面積}

Dubois의 body surface area chart에 依하였다. ${ }^{82}$

2) 肺活量

K.Y.S type (water sealed) spirometer 와 vital capaicty apparatus를 使用하였다.

3) 1 回呼吸量 
결핵 및 호흡기질환 Vol. 21, No 4. October 1974

$<$ 第1表 $>$ 年䟻 哭體格比較

\begin{tabular}{|c|c|c|c|c|}
\hline$\frac{\text { (例續 }}{\text { 查種目 }}$ & & $\begin{array}{c}\text { 操 縱 士 } \\
(271)\end{array}$ & $\begin{array}{c}\text { 鐄 夫 } \\
\text { (47) }\end{array}$ & $\begin{array}{c}\text { 海 } \quad \text { 女 } \\
(20)\end{array}$ \\
\hline 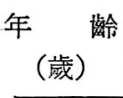 & & $\begin{array}{r}28.08 \pm \\
22-\end{array}$ & $\begin{array}{c}32.20 \pm 8.30 \\
18-45\end{array}$ & 33 \\
\hline$(\mathrm{cm})^{\frac{\mathrm{E}}{\mathrm{K}}}$ & & & & \\
\hline $\begin{array}{l}\text { 重 } \\
(\mathrm{kg})\end{array}$ & 範垉圍 & $48.6-$ & $\begin{array}{r}59.20 \pm 6.80 \\
50.0-73.0\end{array}$ & $\begin{array}{r}122.60 \pm 3 \\
50.0-67\end{array}$ \\
\hline $\begin{array}{l}\text { 表面積 } \\
\left(\mathrm{m}^{2}\right)\end{array}$ & 範圍 & & & \\
\hline
\end{tabular}

마스크와 one way valve를 通하여 Douglas bag에 採氣하여 gas metar (wet test)로 測定하였다.

\section{4) 最大呼吸量}

마스크와 Douglas bag을 使用하여 15秒間 最大限으 로 길고 빠르게 呼吸한 空氣를 採氣後 4倍로 計算하였 다. ${ }^{93}$

\section{III. 成 續}

\section{1. 肺容積의 比較}

1) 呼吸數는 第 2 尝에서 보는 바와같이 操稰士는 1 分
에 平均 17 , 鍰夫는 平均 16 이었고,

2) 一回 呼吸量은 各各 $500 \mathrm{ml}( \pm 79.1)$ 이었다.

3) 肺活量에 있어서는 操縱士에서 本均 $4,953 \pm 501.3 \mathrm{ml}$ 였으며, 鐄夫에서는 平均 $3,232 \pm 844.0 \mathrm{ml}$ 이였다.

4) 最大呼吸量을 보면 各各 本均 $106.65 \mathrm{l} / \mathrm{min}( \pm 14$, $479)$ 와 $118.00 \mathrm{l} / \mathrm{min}( \pm 4,720)$ 로서 操綎士 및 鐄夫가 近似한 값을 나타낸다.

5) 呼吸停止 時間에서는 鐄夫에서 平均 $54.0 \pm 8.36$ 秒

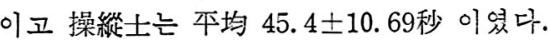

\section{2. 肺活量 標準值와의 差異}

肺活量에 있어서 Baldwin氏 數式 ${ }^{10}$ 에 依한 標灌值 $4.113 \mathrm{~m} l$ 에 比하여 操縱士의 實測平均值 $4,953 \mathrm{~m} l$ 는 約 $20 \%$ 의 높은 값을 나타내고 있으며 鐄夫에 實测本均值 $3.232 \mathrm{~m} l$ 에 있어서는 오히려 $21 \%$ 의 낮은 값을 보여 준 다. 또 海女에서는 實測本均値 $3.439 \mathrm{~m} l$ 인데 ${ }^{4}$ 이는 操 縱士 값과 같이 標準值에 比하여 約 $25 \%$ 높은 成績을 보여 준다. (第 3表)

\section{3. 肺活量 係數手 比較}

肺活量 係數로서 比較하면 本 檢査에 · 있어서 操緃士 에서 2. $88 \pm 0.268$ 인 가장 높은 값을 보여 주며 다음은 大學生의 $2.69 \pm 0.044$, 體育人 $2.50 \pm 0.040$, 海女의 $2.23 \pm 0.082$ 에 順이며 鐄夫가 $1.98 \pm 0.453$ 으르 最低의 값을 나타년다(第4表 및 第1圖).

<第2表 $>$ 各種肺容積의 比較

(B.T.P.S)

\begin{tabular}{|c|c|c|c|c|}
\hline 檢査種目 & 列數） & $\begin{array}{c}\text { 操 } \\
\qquad \begin{array}{c}\text { 縱 } \\
(271)\end{array}\end{array}$ & 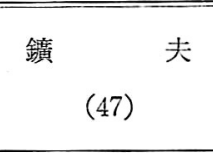 & 海 \\
\hline $\begin{array}{l}\text { 吸 } \\
\text { (分) }\end{array}$ & $\begin{array}{l}\text { 平均 } \\
\text { 範圍 }\end{array}$ & $\begin{array}{c}17.1 \pm 2.71 \\
11-22\end{array}$ & $\begin{array}{c}16.6 \pm 1.82 \\
12-20\end{array}$ & $\begin{array}{c}14.1 \pm 0.60 \\
10-18\end{array}$ \\
\hline $\begin{array}{cc}\text { 棜 活 } \\
(\mathrm{m} l)\end{array}$ & $\begin{array}{l}\text { 本均 } \\
\text { 範圍 }\end{array}$ & $\begin{array}{l}4,953 \pm 501.3 \\
3,780-6,170\end{array}$ & $\begin{array}{l}3,232 \pm 844.0 \\
2,017-4,000\end{array}$ & $\begin{array}{l}3,439 \pm 103.0 \\
2,380-4,671\end{array}$ \\
\hline $\begin{array}{c}\text { 豫 備 四 氣 量 } \\
(\mathrm{m} l)\end{array}$ & $\begin{array}{l}\text { 本均 } \\
\text { 範圈 }\end{array}$ & $\begin{array}{l}2,362 \pm 448.6 \\
1,170-3,650\end{array}$ & $\begin{array}{l}1,887 \pm 224.3 \\
1,205-2,624\end{array}$ & $\begin{array}{l}1,804 \pm 54.0 \\
1,084-2,846\end{array}$ \\
\hline $\begin{array}{c}\text { 豫 備 呼 氣 量 } \\
(\mathrm{m} l)\end{array}$ & $\begin{array}{l}\text { 平均 } \\
\text { 範圍 }\end{array}$ & $\begin{array}{l}2,115 \pm 390.4 \\
1,100-3,020\end{array}$ & $\begin{array}{r}1,050 \pm 110.0 \\
923-2,154\end{array}$ & $\begin{array}{r}1,050 \pm 56.0 \\
947-2,635\end{array}$ \\
\hline $\begin{array}{c}\text { 一 回 呼 吸 量 } \\
(\mathrm{m} l)\end{array}$ & $\begin{array}{l}\text { 平均 } \\
\text { 範圍 }\end{array}$ & $\begin{array}{l}496 \pm 91.4 \\
353-780\end{array}$ & $\begin{array}{l}495 \pm 67.2 \\
389-693\end{array}$ & $\begin{array}{l}585 \pm 34.0 \\
456-654\end{array}$ \\
\hline $\begin{array}{c}\text { 最 大 呼 吸 量 } \\
(l / \mathrm{min})\end{array}$ & $\begin{array}{l}\text { 平均 } \\
\text { 範圄 }\end{array}$ & $\begin{array}{r}106.65 \pm 14.479 \\
80.00-144.85\end{array}$ & $\begin{array}{l}118.00 \pm 4.720 \\
68.00-166.00\end{array}$ & $\begin{array}{r}100.10 \pm 4.500 \\
75.00-143.00\end{array}$ \\
\hline $\begin{array}{c}\text { 呼吸停 止 時 間 } \\
(\mathrm{sec})\end{array}$ & $\begin{array}{l}\text { 平均 } \\
\text { 範圍 }\end{array}$ & $\begin{array}{l}45.4 \pm 10.69 \\
31-95\end{array}$ & $\begin{array}{c}54.0 \pm 8.36 \\
35-81\end{array}$ & $\begin{array}{c}72.0 \pm 12.00 \\
49-103\end{array}$ \\
\hline
\end{tabular}


<第3表 $>$ 肺活量標準值와의 差異

(B.T.P.S)

\begin{tabular}{|c|c|c|c|c|}
\hline 檢查 & 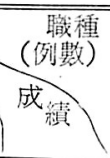 & $\begin{array}{c}\text { 操 縱 士 } \\
(271)\end{array}$ & $\begin{array}{c}\text { 鐄 夫 } \\
(47)\end{array}$ & $\begin{array}{c}\text { 海 女 } \\
(20)\end{array}$ \\
\hline \multirow{3}{*}{$\begin{array}{l}\text { 脯 } \\
\text { 活 } \\
\text { 龺 } \\
(\mathrm{m} l)\end{array}$} & 測 定 值 & $4,953 \pm 501$. & $3,232 \pm 844.0$ & $3,439 \pm 103.0$ \\
\hline & 標準 值 & 1, $113 \pm 125$ & $4,113 \pm 125.0$ & $2,810 \pm 39.0$ \\
\hline & $\begin{array}{l}\text { 測定值 } \\
\text { 票準犆 } \\
100(\%) \\
100(\%) \\
\end{array}$ & 120.44 & 78.55 & 125.00 \\
\hline
\end{tabular}

※ 標淮值: [27.63-(0.112×age)]身長(海女에 있어서

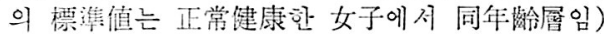

<第 4 表> 胡活量: 倸數의 比䡆

\begin{tabular}{|c|c|c|c|c|c|}
\hline 報告者 & 著 者 & 著 者 & 洪 & 徐 等 & 李 等 \\
\hline 被檢者 & 操縱士 & 䥊 大 & 海 女 & 體育人 & 大學生 \\
\hline 例 频 & 271 & 47 & 20 & 66 & 51 \\
\hline 做 活 量 & $\begin{aligned} 2.88 \pm \\
0.268\end{aligned}$ & $\begin{array}{c}1.98 \pm \\
0.453\end{array}$ & $\mid \begin{array}{c}2.23 \pm \\
0.082\end{array}$ & $\begin{array}{r}2.50 \pm \\
0.040\end{array}$ & $\begin{array}{l}2.69 \pm \\
0.044\end{array}$ \\
\hline 百分率 & 100.00 & 61.80 & 77.43 & 86.81 & 93.40 \\
\hline
\end{tabular}

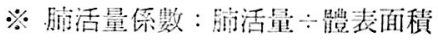

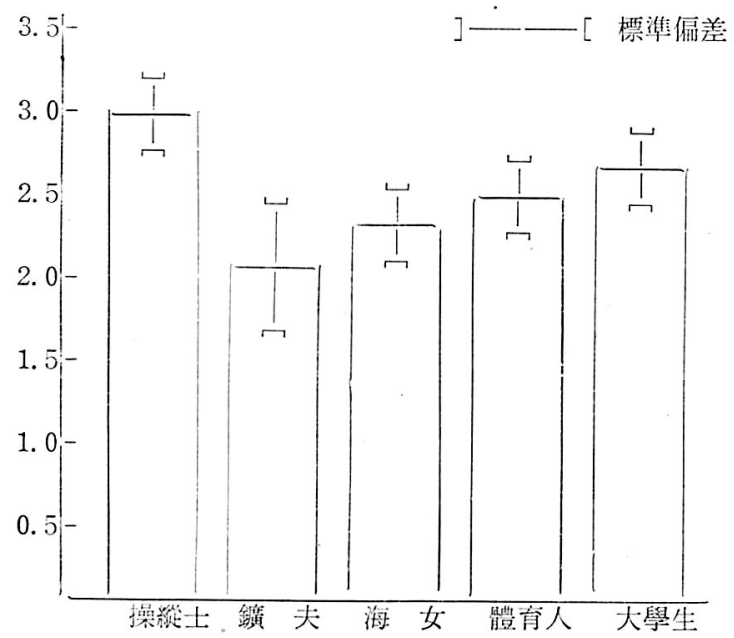

第1圖 肺活量係數手 比較

\section{4. 最大呼吸量 標準値와의 差異}

操綎士에 있어 서 本均 $106.65 l( \pm 14,147)$ 의 測定值 에서 標準値 $122.65 l$ ( \pm 7.364 )에 比하면 $13 \%$ 의 낮은 값을 나타냈으며 이는 被檢者가 最大限應하여 주지 않 은 點으로 思籼되며 鐄夫에 서는 標準值에 거의 가까운 平均 118.00l $( \pm 4,720)$ 를 보여주고 있으며 海女에 있 어서는 約 $30 \%$ 程度 높은 平均 $80.20 l( \pm 2,400)$ 를 보 여 준다(第 5 表).
결핵 및 호홉기질환 Vol. 21, No 4. October 1974

<第 5 表 $>$ 最大呼吸量標淮值와의 差異 (B.T.P.S)

\begin{tabular}{|c|c|c|c|c|}
\hline & 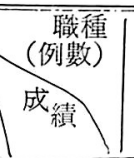 & $\begin{array}{c}\text { 操 縱 士 } \\
(271)\end{array}$ & $\begin{array}{c}\text { 鋖 夫 } \\
(47)\end{array}$ & $\begin{array}{l}\text { 海 女 } \\
(20)\end{array}$ \\
\hline \multirow{3}{*}{$\begin{array}{l}\text { 最 } \\
\text { 呼 } \\
\text { 囬 } \\
\text { 量 }\end{array}$} & 測 定 值 & $\begin{array}{r}106.65 \pm \\
14,479\end{array}$ & $\begin{array}{r}118.00 \pm \\
4,720\end{array}$ & $\begin{array}{r}100.10 \pm \\
4,500\end{array}$ \\
\hline & 標 準 值 & $\begin{array}{r}122.65 \pm \\
7,354\end{array}$ & $\begin{array}{r}122.65 \pm \\
7,364\end{array}$ & $\begin{array}{c}80.20 \pm \\
2,400\end{array}$ \\
\hline & $\left|\begin{array}{|c|}\text { 票準值 } \\
\text { 測定值 } \\
100(\%)\end{array}\right|$ & $87: 11$ & 96.29 & 128.30 \\
\hline
\end{tabular}

※ 海女에 있어서의 標淮値는 正常健康한 女子에서 同 年路層。品.

\section{5. 呼吸停止時間의 比較}

Breath holdimg time에서는 海女가 $72.0 \pm 12.00$ 秒로 서 가장 길었으며 다음이 體育人에 $55.2 \pm 2.09$ 秒와 鐄 夫에 $54.0 \pm 8.36$ 秒이며 大學生 $44.5 \pm 2.08$ 秒와 操縱士 $45.4 \pm 10.69$ 秒가 가장 짧은 順으로 나타낸다. (第 6 表 哭第2圖)

<第6表> 呼吸停止時間의 比較

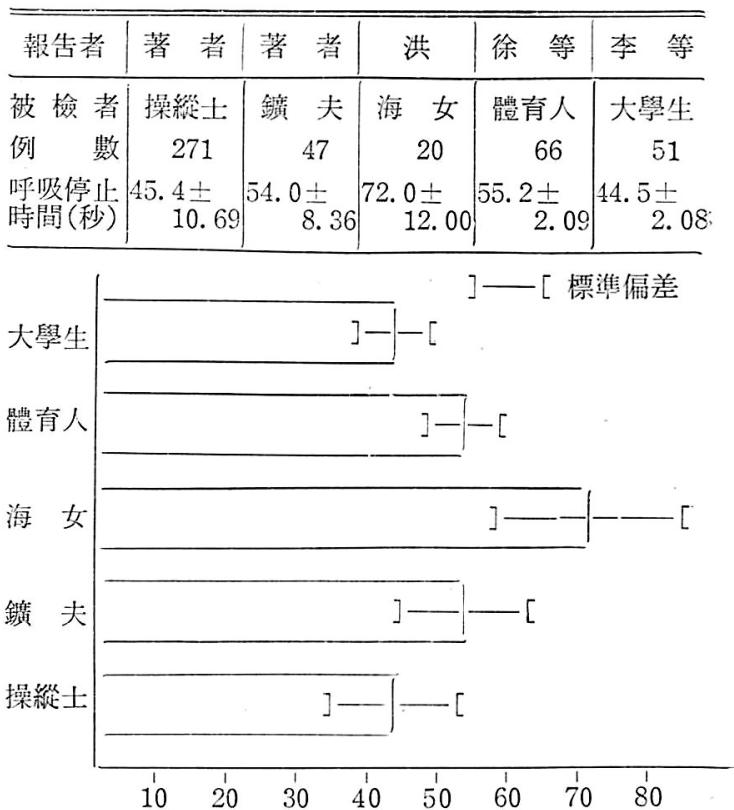

<第2圖> 呼四停止 時間의 比較

(sec)

\section{IV. 考按}

1849年 Hutchinson ${ }^{10,11)}$ 이 肺活量 測定의 臨床的 意 義를 提唱한 以來 肺活量은 오늘날 까지 心臟 및 肺의 疾病存在의 表示 뿐만 아니라 胡와 胸廓의 呼吸能力의 重要한 指表임은 臨床家와 生理學者가 認定하는바 이 다.

肺活量은 性別, 年茀, 職業, 人種, 體格, 姿势, 其 
他의 圭要因子의 影響을 받으며 ${ }^{11)}$ 이中에서도 體格의 大小에 따라서 肺活量의 포가 크다. 特히 1915年 Dubis ${ }^{8,11}$ 가 體表面積 算出式을 發表㘶 以來 1917年 Peabody \& Wentworth, 1919年 Dreyer, 1920 1924年 West, 表面積 算出 및 Lemon \& Moersch에 依하여 肺 活量은 다른 어느 生體測定値 보다도 體表面積과 가장 關係가 깊다고 報告하였다. ${ }^{11)}$ 本 檢查成續에서 體表面 積과 脑活量을 보면 操緃士에 서 體表面積이 $1,725 \mathrm{~m}^{2}$ 에 서 肺活量이 $4,953 \mathrm{~m} l$ 이며 鑛夫와 海女가 各各 $1,690 \mathrm{~m}^{2}$ 에 $3,232 \mathrm{~m} l$ 와 $1,540 \mathrm{~m}^{2}$ 에 $3,439 \mathrm{~m} l$ 이였다.

肺活量과 標準值와의 關䋆를.보면 海女群은 標準值 $2,810 \mathrm{~m} l$ 보다 $25 \%$ 나 높은 $3,439 \mathrm{~m} l$ 를 나타내고 있다.

이는 肺活量을 構议하고 있는 expiratory reserve volume과 inspiratory capacity를 比較함으로서 海女 에서 肺活量이 增加간 것은 inspiratory capacity의 增 加로 因한 것임을 알 수 있다. ${ }^{4)}$

安靜 臥位時 普通呼氣後 呼吸을 中止시키고 얼마동 안 停止할 수 있는가를 觀察桀 結果 海女에서는 約 20 秒나 더 견디어 낸다. 이 停止時間게는 個人差가 比較 的 크기 때문에 統計學的으로 보면 他職锺과의 差가 그리 큰 意義를 가진 것은 아니나 海女에서 安淨侍 酸 素 消費量이 높다는 事宷을 考虑하견 이와같은 差는 더욱 意義를 갖게 된다. ${ }^{4)}$

生理學的으로 볼때 呼吸을 中止하게 하는 因子는 $\mathrm{PCO}_{2}$ 의 上昇, $\mathrm{PO}_{2}$ 의 低下 및 肺容積의 萎縮等 3 가지 를 들수 있으며, 따라서·海女에서 停止時間이 길다는 事實을 證明하기 爲하여서는 呼吸停止를 그 以上 더 繼續할 수 없을 때의 肺容積 및 肺胞內 氣體를 探取하 여 $\mathrm{PAO}_{2}$ 및 $\mathrm{PACO}_{2}$ 를 測定하지 않으면 안된다. 他職 種 보다 海女에 있어서의 停止 時間이 길다는 것은 $\mathrm{PCO}_{2}$ 上昇에 對해서 感受性의 鈍해 졌던지 或은 $\mathrm{PO}_{2}$ 의 低下에 對해서 感受性이 소스을로 低下 되었던지 그中 하나가 될 것으로 推測된다. ${ }^{4,8,103}$

呼吸數 및 1回呼吸量에 있어서는 操縱士와 鐄夫가 大同小異한 값을 보여 주나 海女에서는 呼吸數가 多少 떨어지는 反面에 1回呼吸量은 若干 많은 값을 보여 줌 으로 即, 分時呼吸量으로 計算하뗜 거의 同一한 成績 을 나타낸다. ${ }^{12)}$

\section{V. 結 論}

空軍 操綎士 271 名과 鑛夫 47 名에 對하여 肺機能檢 査를 하여 다음과 같은 結果를 얻었다.

1. 呼吸數에 있어서는 操絽士에서 每分間 平均 17 이였 으며 鑛夫에서는 每分間 平均 16 이었다.

2. 肺活量에서는 操縱士에 있어서는 約 平均 $5 l$ 였으며
鐄夫에서는 約 平均 $3.2 l$ 로서 이는 標準徝에 比하여 $20 \%$ 程度 높고 낮은 값을 나타넌다.

3. 1回呼吸量은 平均 $500 \mathrm{~m} l$ 이며 最大呼汲量은 約 本均 $110 l$ 이였다. (操珿士와 鑛夫같이)

4. 呼吸停止時間은 平均 45 秒와 54 秒르서 錮夫 쪽이 約 10 秒 높은 값으로 나타냈다.

\section{REFERENCES}

1. Im, B. I.; Studies on the Vital Capaity and the Maximal Breathing Capacity on the Korean, Korean J. Int. Med. , 8:17, 1965.

2. Kim, D.S., Lee, S.H. and Park, H.M.: 健康韓國 人이 脑容積, 最大換氣量 및 秒洔踥活量에 對하여, 大邱醫學雜誌, $2: 45,1959$.

3. Kim, P.K., Park, H. K. and Kil, E.H.: 體育選手 . 의 肺機能檢查, New Med. J., $6: 9,1963$.

4. Hong, S.K.: 韓或海女의.呼睲理學的 呼究, ROKAF J. Aviat. Med., $9: 1,1961$.

5. Choo, Y. et al: 成長期 韓國人 男 - 女 基礎體力向 上에 關㸃 研究. 大韓生理學曾誌, $4: 2,1970$.

6. Kim, C:S.: Study on Physiological Age of Korean, Now Med. J., 6: 7, 1953.

7. Park, C. et al: 運動選手手 心肺聯能 및 㖶動代謝, J. Korean Med. Ass. 7 : 10, 1964.

8. Comroe, Forsta, Dubjis, Briscoe and Carlsen: Clinical Physiology andPulmonary Function Test, The Lung, 2Ed., Year Book Pub. Chiago 1963.

9. Sihm, D.W.: 高温罢境이 肺機能에 미치는 影響, 航空醫學 第12卷 第1號 1964.

10. Consolajio. Johnson, Peiora: Physiological Measurements of Metabolic Function in Man,. Mc Graw Hill 1963

11. Lee, D.K. and Kim, K.H.: 士官生從手 體表面積 과 肺活量의 相關關係. ROKAF J. Aviat. Med., $1: 5-6,1953$.

12. Han, Y. C.: Pulmonary Function Tests, J. Korean Med. Ass. $5:$ 7, 1962. 